\title{
Cup anemometer overspeeding
}

\author{
Busch, N.E.; Kristensen, Leif
}

Publication date:

1976

Document Version

Publisher's PDF, also known as Version of record

Link back to DTU Orbit

Citation (APA):

Busch, N. E., \& Kristensen, L. (1976). Cup anemometer overspeeding. Risø National Laboratory. Denmark. Forskningscenter Risoe. Risoe-R No. 339

\section{General rights}

Copyright and moral rights for the publications made accessible in the public portal are retained by the authors and/or other copyright owners and it is a condition of accessing publications that users recognise and abide by the legal requirements associated with these rights.

- Users may download and print one copy of any publication from the public portal for the purpose of private study or research.

- You may not further distribute the material or use it for any profit-making activity or commercial gain

- You may freely distribute the URL identifying the publication in the public portal

If you believe that this document breaches copyright please contact us providing details, and we will remove access to the work immediately and investigate your claim 
$\ddot{2}$

t)

Danish Atomic Energy Commission

Research Establishment Risø

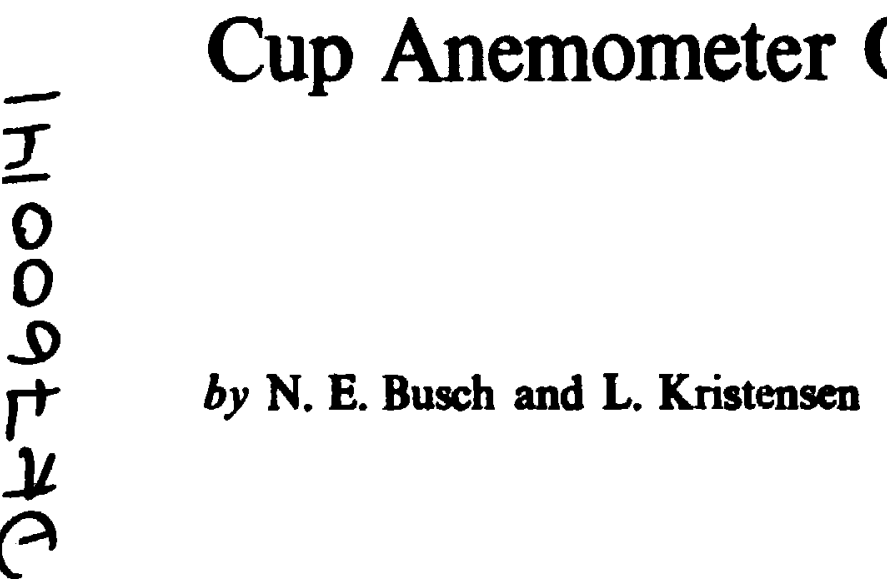

March 1976 
UDC 533.6.08: 551.508.5 


\title{
Cup Anemometer Overspeeding
}

$$
\text { by }
$$

N. E. Busch and L. Kristensen

Danish Atomic Energy Commission

Research Establishment Risø

Phyaics Department

\begin{abstract}
Statistical considerations are applied to a general equation of motion for cup anemometers in a turbulent wind. It is shown that the relative overspeeding $\Delta S / S$ can be expressed as: $\Delta S / S=I_{B}{ }^{2} J_{B}\left(\ell_{\sigma} / \Delta_{s}\right)+c I_{w}{ }^{2}$. where $I_{8}$ and $I_{w}$ are the horizontal and the vertical turbulence intensities, respectively. The function $J_{8}$ depends on the shape of the 8 pectrum of horizontal turbulent energy, $\ell_{0}$ is the distance constant for the anemometer and $\Lambda_{s}$ is a characteristic length scale of the horizontal turbulence. The conscant $c$ is of order unity.

If $A_{s}$ is suitably chosen as the scale of the energy-containing eddies, then $J_{B}$ is satiefactorily approximated by $J_{B}=\left(1+\ell_{g} / \ell_{0}\right)^{-1}$ in most atmospheric applications.
\end{abstract}


CONTENTS

Page

1. Introduction $\ldots \ldots \ldots \ldots \ldots \ldots \ldots \ldots \ldots \ldots \ldots \ldots \ldots \ldots \ldots \ldots$

2. Cup Anemometer Dymamics $\ldots \ldots \ldots \ldots \ldots \ldots \ldots \ldots \ldots \ldots \ldots$

3. Scale Relations $\ldots \ldots \ldots \ldots \ldots \ldots \ldots \ldots \ldots \ldots \ldots \ldots \ldots \ldots \ldots$ 8

4. Cancluding Remarks $\ldots \ldots \ldots \ldots \ldots \ldots \ldots \ldots \ldots \ldots \ldots \ldots . \ldots 18$

References $\ldots \ldots \ldots \ldots \ldots \ldots \ldots \ldots \ldots \ldots \ldots \ldots \ldots \ldots \ldots \ldots \ldots . . \ldots$ 


\section{INTRODUCTION}

The cup anemometer is widely used because it is a simple, sturdy and reliable instrument that generally only requires a minimum of maintenance. A further major advaitage from an operational point of view is that there is no need for alignment into the wind direction, so the cup anemometer is ideal for continuous measurements. A disadvantage is the co-called overspeeding caused by the nonlinear response to fluctuating winds. Cup anemometers respond more quickly to an increase in the wind speed than to a decrease of the same magnitude. Consequently, in a turbulent flow the mean wind speed will be overestimated, if the instrument has been calibrated in a laminar now. It has been shown by Busch (1965) that the overestimation is proportional to the variance of the horizontal wind speed divided by the square of the mean wind speed, i. e.. proportional to the square of the horizontal turbulence intensity. However, it seems intuitively clear that a fast-responding cup anemometer will show less overspeeding than a slow-responding cup anemometer, if the two are exposed to the same wind field. In the following we establish a relation between overspeeding, turbulence intensity, and the ratios between the length scale of the instrument and the scales of the turbuience.

\section{CUP ANEMOMETER DYNAMICS}

We shall take our starting point in the work of Wyngaard et al. (1971), in the following referred to as WBL. They use the rather general equation of motion

$$
\operatorname{IR} \dot{\boldsymbol{Q}} \equiv \operatorname{IR} \frac{\mathrm{d} \rho}{\mathrm{dt}}=\mathrm{T}(\mathrm{R} \Omega, S, W)
$$

Here I denotes the moment of inertia, $R$ the cup arm, o the angular velocity, and $T$ the torque exerted on the instrument by the wind fleld with the total horizontal component $S$ and the vertical component $W$. The angular position of the cup wheel does not appear in the equation, because 0 and $T$ represent quantities that are smoothed over the period of time that it tal es the cup wheel to turn the angle $2 \pi / N$, where $N$ is the number of cups.

In a steady, horizontal wind, the torque is zero, so we have

$\dot{0}=0$ 
and

$T\left(R Q=R \propto_{0^{\circ}}, S=S_{\sigma^{\circ}} W=0\right)=0$.

We consider the case in which $S(t)$ and $W(t)$ are second-order, stationary, stochastic processes satisfying

$$
\langle s\rangle=s_{0}
$$

and

$$
\langle\mathbf{w}\rangle=\mathbf{0} \text {, }
$$

where the brackets here and in the following denote ensemble averaging.

The fluctuating quantities $s(t), \theta(t)$ anc $\omega(t)$ are defined by

$$
\begin{aligned}
& s(t)=S(t)-S_{0}, \\
& \theta(t)=w(t) / S_{0}
\end{aligned}
$$

and

$$
w(t)=c(t)-u_{0}
$$

where $Q_{0}$ can be found by solving (3). The ensemble means of $s(t)$ and $\theta(t)$ are zero.

From various symmetry considerations, WBL argued that the secondorder dynamic equation for the nuctuating quantities can be written

$$
\tau_{0} \frac{\dot{\omega}}{g_{0}}+\frac{\omega}{Q_{0}}=\frac{s}{s_{0}}+a \frac{s^{2}}{s_{0}^{2}}-b \frac{\omega}{s_{0}} \frac{\omega}{q_{0}}-(a-b) \frac{\omega^{2}}{a_{0}^{2}}+c \theta^{2},
$$

where $8, b$ and $c$ are constants in the sense that they do not depend on the nuctuating quantities, and $\tau_{0}$ is a characteristic time. For later convenience, we introduce the so-called distance constant $l_{0}$ by

$$
\ell_{0}=S_{0} T_{0}
$$

In order to find an expreasion for the overwpeeding we take the ensomble average of (9): 


$$
\frac{\langle u\rangle}{\varepsilon_{0}}=\frac{\left\langle a^{2}\right\rangle}{s_{0}^{2}}-b \frac{\langle a\rangle}{s_{0} \omega_{0}}-(a-b) \frac{\left\langle u^{2}\right\rangle}{a_{0}^{2}}+c\left\langle a^{2}\right\rangle .
$$

The left-hand side of (11) is the relative overspeeding, since it is the mean of the excess response divided by the response to a constant wind speed of magnitude $S_{0}$. Unfortunately, the right-hand side conthins terms proportional to $\left\langle(s \omega\rangle\right.$ and $\left\langle\omega^{2}\right\rangle$. These terms cannot be evaluated without additional information on $\omega(t)$.

To overcome this problem, we assume that $|s| / S_{o}|\omega| / 0_{0}$ and $|0|$ are 80 small that the solution to the linear perturbation equation

$$
\frac{l_{0}}{s_{0}} \frac{\omega}{\sigma_{0}}+\frac{\omega_{0}}{\sigma_{0}}=\frac{\sigma}{s_{0}}
$$

can be used to relate $\langle s \omega\rangle$ and $\left\langle\omega^{2}\right\rangle$ to $\left\langle s^{2}\right\rangle$ with sufficient accuracy.

The solution to (12) with the initial condition $\varphi(-\infty)=0$ is

$$
\frac{\omega}{g_{0}}=\frac{1}{l_{0}} \int_{0}^{\infty} s\left(t-t^{\prime}\right) \exp \left(-\frac{s_{0}}{\Sigma_{0}} t^{\prime}\right) d t^{\prime}
$$

It is easily shown that

$$
\frac{\left\langle\omega^{2}\right\rangle}{\theta_{0}^{2}}=\frac{\langle\theta \omega}{s_{0} c_{0}}=\frac{\alpha_{0}}{s_{0}^{2}} \frac{s_{0}}{l_{0}} \int_{0}^{\infty} p_{8}(\tau) \exp \left(-\frac{s_{0}}{l_{0}} \tau\right) d \tau,
$$

where $\sigma_{g}^{2}=\left\langle a^{2}\right\rangle$ is the variance and $\rho_{g}(\tau)$ the autocorrelation function for the time series $s(t)$.

Uaing Taylor's hypothesis to convert the temporal autocorrelation function to a spatial autocorrelation function, we can write the expression (11) for overopeeding

$$
\frac{\langle\omega\rangle}{u_{0}}=\frac{\sigma_{s}^{2}}{s_{0}^{2}}\left(1-\frac{1}{x_{0}} \int_{0}^{\infty} \omega_{0}(x) \exp \left(-x / \ell_{0}\right) d x\right)+c \frac{\sigma_{w}^{2}}{s_{0}^{2}}
$$

where

$$
\omega_{8}(x)=p_{g}\left(x / s_{0}\right),
$$


and $0^{2}$ is the veriance of the vertical wind velocity companent.

If we introduce the speed energy spectrum $\bullet_{g}(n)$ by

$$
\theta_{8}(x)=\frac{1}{2 \pi} \int_{-\infty}^{\infty} n_{8}(x) \exp (-i x x) d x
$$

then (15) may also be written

$$
\frac{\langle u}{\alpha_{0}}=a \frac{0^{2}}{s_{0}^{2}} \int_{-\infty}^{\infty} \frac{\left(l_{0} x\right)^{2}}{1+\left(\ell_{0} x\right)^{2}} \theta_{\theta}(x) d x+c \frac{\sigma_{w}^{2}}{s_{0}^{2}}
$$

From wind tunnel measurements, WBL found that $a=0.96$ and $c=0.67$ for their cup anemometer. Hence, both horizontal and vertical wind nuctuations should give rise to an overestimation of the mean wind speed. Indeed, more detailed theoretical considerations seem to show that a should be close to unity.

\section{SCALE RELATIONS}

Eq. (18) forms the basis for our evaluation of the overspeeding of a cup anemometer. As demonstrated by WBL, the coefficients a and $c$ for a given cup anemometer can be determined once and for all in a wind tunnel. In each application we still have to estimate the variances $\sigma_{s}^{2}$ and $\sigma^{2}$ in addition to the quantity

$$
J_{8}=\int_{-\infty}^{\infty} \frac{\left(l_{0} x\right)^{2}}{1+\left(l_{0} x\right)^{2}} \bullet_{B}(x) d x
$$

The distance constant $\ell_{0}$ can also be determined in a laminar wind tunnel, whereas the speed spectrum $\bullet_{B}(n)$ depends on the actual wind fleld.

As an example, let wo consider a situation with small wind direction Auctuations. In this case the mean wind speed is approximately equal to the mean of the wind velocity component $U_{0}$ in the mean wind direction. The reason is that up to the third order in the horizontal components $u$ and $v$ of the fluctuating part of the wind vector, the following relation holds

$$
s_{0}=u_{0}\left(1+\frac{1}{2}\left\langle v^{2}\right\rangle / v_{0}^{2}\right)
$$


To the anme approdimation, we have a relation between the Auctuating parts of $S$ and $u$ and $v$ :

$$
s=u+\frac{1}{2}\left(v^{2}-\left\langle v^{2}\right\rangle\right) / u_{0}
$$

We neglect the second-order terms in (20) and (21) and set the spectrum ${ }_{s}(w)$ equal to the oise-dimensional horisontal spectrum $F_{11}(w)$ for $u$ :

$$
g(x)=E_{11}(x)
$$

If the fuctuating quantity $u$ has an integral scale ${ }_{u}$, and if the spectrum $F_{11}(x)$ fulfils certain rather weak conditions wich are actually fulfilled in most atmospheric applications, then for $A_{u}\left\langle\left(l_{0}\right.\right.$ we have

$$
\begin{aligned}
J_{8} & =\int_{-\infty}^{\infty} \frac{\left(l_{0} x\right)^{2}}{1+\left(l_{0} x\right)^{2}} F_{11}(x) d x=1-\int_{-\infty}^{\infty} \frac{F_{11}(x) d x}{1+\left(l_{0} x\right)^{2}} \\
& \approx 1-\frac{\Lambda_{u}}{\pi} \int_{-\infty}^{\infty} \frac{d x}{1+\left(l_{0} x\right)^{2}}=1-\Lambda_{u} / l_{0} .
\end{aligned}
$$

If there is no integral scale, or if it is not much smaller than the distance constant, then this approximation is invalid. Instead, we may assume, for instance, that an inertial subrange exdsts, and that the corresponding expression for the one-dimensional spectrum,

$$
F_{11}(x)=\frac{9}{55} \cdot \frac{\epsilon^{2 / 3}}{\sigma_{u}^{2}}|x|^{-5 / 3} .
$$

can be used over a sufflciently wide a range. The meanings of the quantities in (24) are: 6 is the rate of viscous disetpation of turbulent energy, o the root mean square of $u$, and a the so-called Kolmogorov constant, which is approximately equal to 1.5 . The expresetion for $J_{s}$ becomes

$$
J_{t}=\frac{18}{b s} \frac{\pi}{\sqrt{3}} R e^{-2}\left(\frac{l g}{q}\right)^{2 / 3} .
$$

where

$$
\left(0^{3} / 6\right)^{1 / 4}
$$


is the Kolmogorov dissipation scale and Re the Reynolds number based on 7. ${ }^{\prime} u$, and the kinematic viscosity $v$.

Eqs. (23) and (25) show examples of how overspeeding may be related to the ratios between the distance constant and the length scales of the horizontal turbulence.

Thy ough (25) we may also relate the overspeeding to the friction velocity $u$ and the height of measurement $z$, provided that the MoninObukhov similarity hypothesis holds and that there is local balarce between the production of turbulent energy and viscous dissipation. Then we have

$$
\frac{\langle\omega\rangle}{t_{0}}=a \frac{18}{35} \frac{\pi}{\sqrt{3}} \frac{a}{k^{2 / 3}} \frac{u_{0}^{2}}{s_{0}^{2}}\left(\nabla_{m}\left(\frac{z}{L}\right)-\frac{z}{L}\right)^{2 / 3} \frac{l}{z}^{2 / 3}+c \frac{0^{2}}{s_{0}^{2}} .
$$

The quantities $k, L$ and $\nabla_{m}$ are the von Karman constant, the MoninObukhov length scale and the non-dimensional wind-shear, respectively.

We may also introduce the function $\downarrow_{m}\left(\frac{2}{L}\right)$ by

$$
t_{m}\left(\frac{z}{L}\right)=\int_{0}^{z / L}\left(1-\varphi_{m}\left(\frac{z^{\prime}}{L}\right)\right) \frac{d z^{\prime}}{z^{\prime}} \text {. }
$$

in which case (27) can be written

$$
\frac{\langle\omega\rangle}{c_{0}}=a \frac{18}{55} \frac{\pi}{\sqrt{3}} k^{4 / 3} \frac{\left(\varphi_{m}\left(\frac{z}{L}\right)-\frac{z}{L}\right)^{2 / 3}}{\left(\ln \frac{z}{z_{0}}-t_{m}\left(\frac{z}{L}\right)\right)^{2}}\left(\frac{l_{0}}{z}\right)^{2 / 3}+c \frac{\bullet_{w}^{2}}{s_{0}^{2}},
$$

where $z_{0}$ denotes the roughness length.

In order to illustrate the meaning of (29) let us assume that the constant a is equal to one, and that $\sigma_{w}^{2}$ is equal to zero. We may rewrite (29) 80 that the relative overspeeding is expressed by

$$
\frac{\langle u\rangle}{\alpha_{0}}=1\left(\ell_{0} / z_{0}, 2 / z_{0}, z / L\right)
$$

For the function $\varphi_{m}\left(\frac{2}{L}\right)$, we adopt the expression 


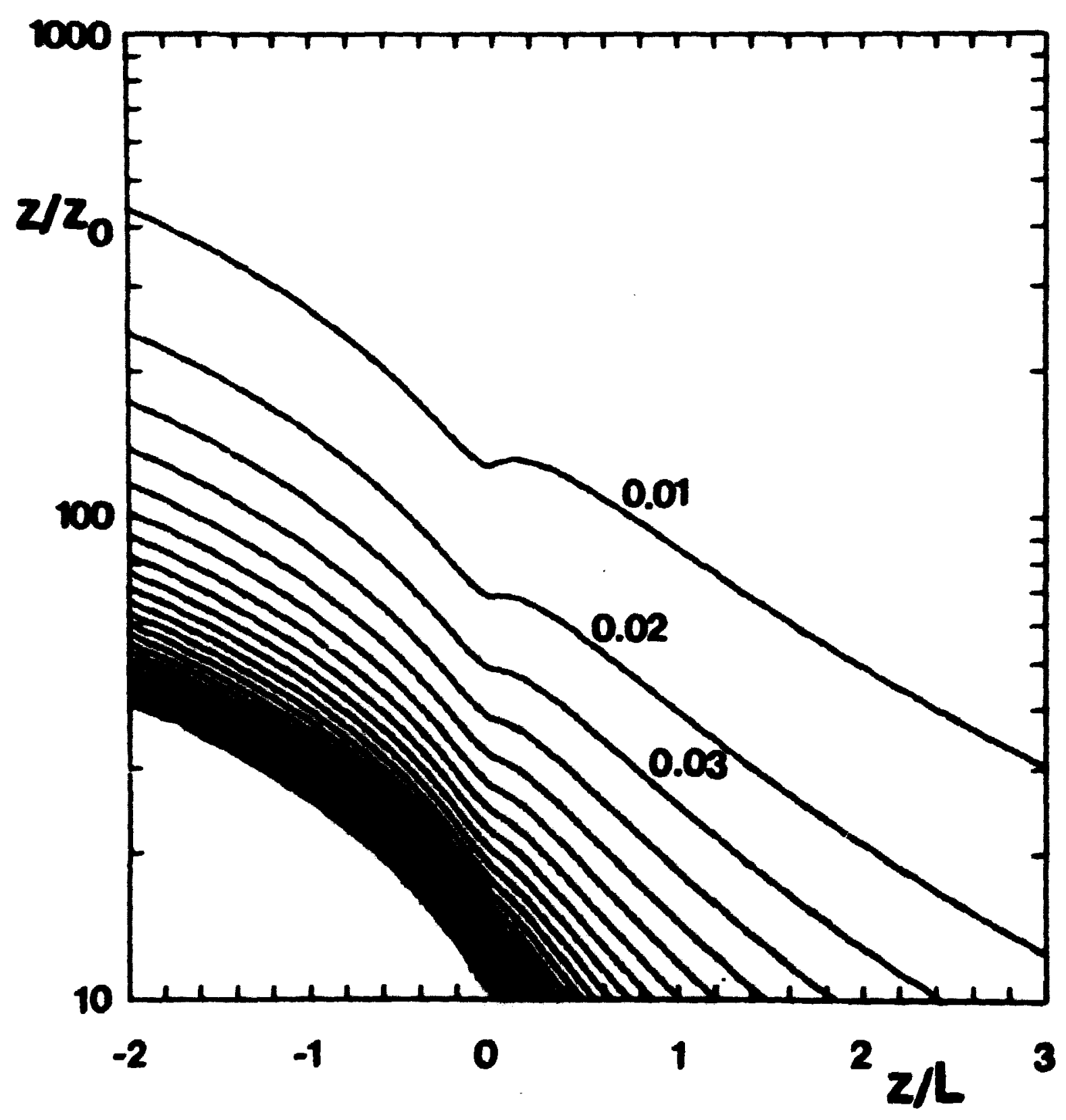

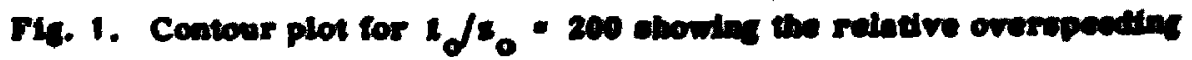
$\langle 0\rangle / 9$. 


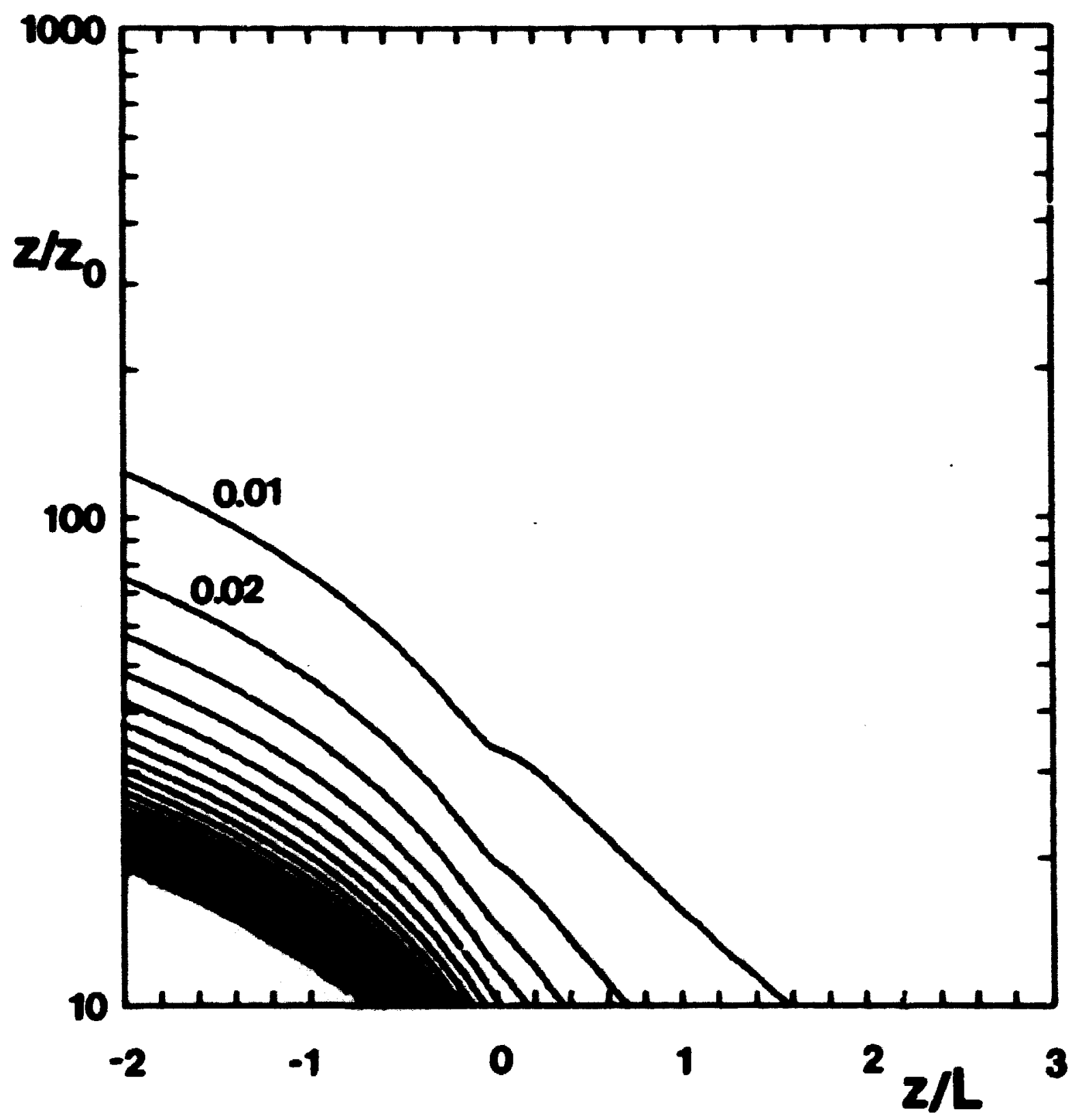

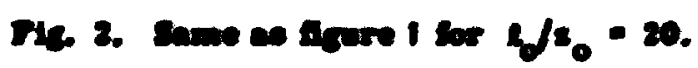




$$
v_{m}\left(\frac{z}{L}\right)= \begin{cases}\left(1-15 \frac{2}{L}\right)^{-1 / 3} & \text { for } \frac{2}{L}<0 \\ 1+5 \frac{2}{L} & \text { for } \frac{2}{L} \geq 0\end{cases}
$$

suggested by Carl et al. (1 973).

The function $f$ is shown in figs. 1 and 2 as contour plots for two different values of $\ell_{0} / z_{0}$.

As an example, suppose that a rather heavy, standard cup anemometer, with distance constant equal to $20 \mathrm{~m}$, is located at a height of $2 \mathrm{~m}$ over a surface with roughness length equal to $10 \mathrm{~cm}$. In this case the relative overspeeding will amount to about $10 \%$ under neutral conditions and to about $20 \%$ for $z / L=-0.2$. For a light cup anemometer with distance constant $2 \mathrm{~m}$, the corresponding numbers are $2.5 \%$ and $4.5 \%$, respectively.

The function $f$ in (30) was evaluated under the assumption that the spectrum is given by (24) for all values of $n$, which implies that the integral scale is infinite. Eq. (30) will become inaccurate when $\ell_{0}$ is not small compared to the length scale of the horizontal turbulence. To estimate the error introduced by use of (24), we select five different expressions for the spectrum $F_{11}(x)$ and compute the ratio between the overspeeding pertaining to each of them and the overspeeding as computed with (24). The five different spectral expression are chosen so that they coincide with (24) in the limit $|x|-\infty$. The five expressions are

$$
\begin{aligned}
& F_{11}^{(1)}(x)=F_{11}^{(0)}\left(x_{0}\right) \frac{\left(\frac{3}{2}\right)^{5 / 3}}{\left(1+\frac{3}{2} \mid \frac{x}{x_{0}}\right)^{5 / 3}} \text { (Kaimal et al., 1972) }
\end{aligned}
$$

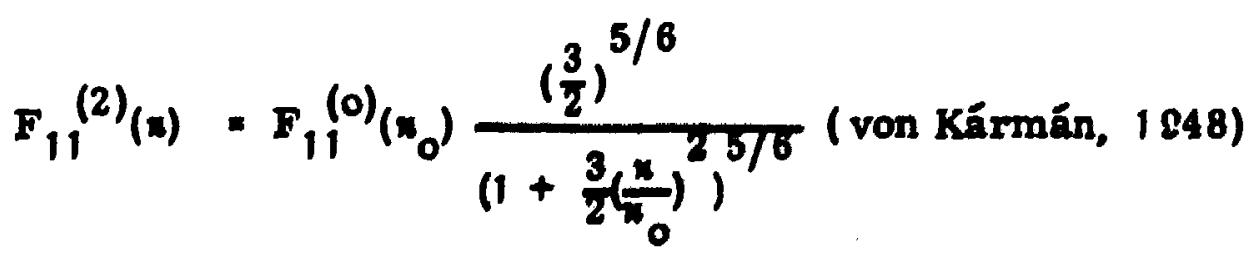

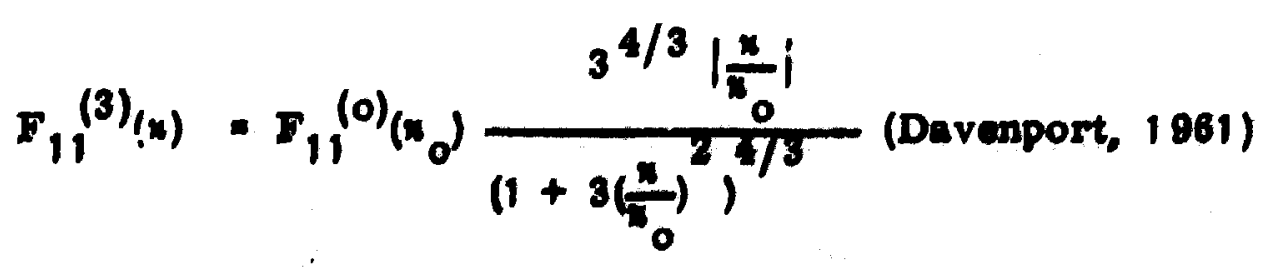




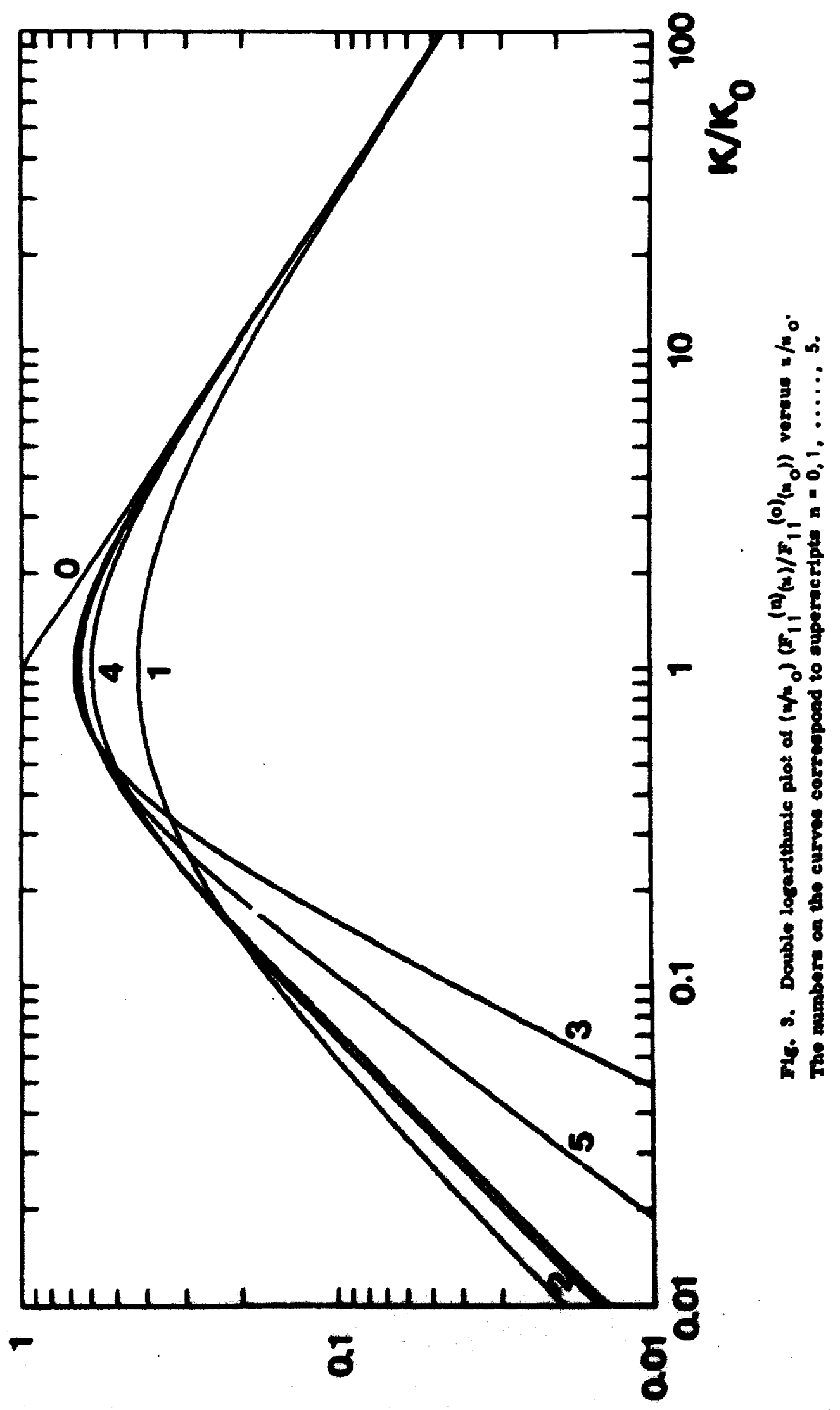




$$
\begin{aligned}
& F_{11}^{(4)}(x)=F_{11}{ }^{(0)}\left(x_{0}\right) \frac{\frac{3}{2}}{\left(1+\frac{3}{2}\left|\frac{x}{x_{0}}\right| 5 / 3\right)} \text { (Kaimal, 1973) } \\
& F_{11}^{(5)}(x)=F_{11}^{(0)}\left(x_{0}\right) \frac{2\left|\frac{x}{x_{0}}\right|^{1 / 3}}{\left(1+2\left(\frac{x}{x_{0}}\right)^{2}\right)}
\end{aligned}
$$

where $F_{11}{ }^{(0)}$ refers to the spectrum (24).

For each spectrum, the peak wave number $\star_{0}$ must be adjusted so that

$$
\int_{-\infty}^{\infty} F_{11}^{(x)}(x) d x=1, n=1,2, \ldots, 5 .
$$

The reciprocal of $x_{0}$ is a horizontal length scale of the turbulence. The five spectra are displayed in $1 \mathrm{~g} .3$, in which the peak positions have been made to coincide for the sake of comparison.

The result of the investigation is shown in fig. 4, where $\mathrm{J}_{8}(\mathrm{n}) / \mathrm{J}_{8}(0)$ is plotted as a function of $l_{0} 0^{*}$. Here $J_{g}(n)$ is given by

$$
J_{0}^{(n)}=\int_{-\infty}^{\infty} \frac{\left(l_{0} x\right)^{2}}{1+\left(l_{0} x\right)^{2}} F_{11}^{(n)}(x) d x
$$

which may be interpreted as the relative overspeeding divided by the square of the turbulence intensity. Fig. 4 shows that we of (24) generally leads to an overestimation of the overspeeding of between 0 and $50 \%$.

Finally, (38) is evaluated for the flve spectral shapes (32) through (36). In addition, the epectrum

$$
F_{11}^{(6)}(x)=\frac{1}{x} \frac{1}{x_{0}} \frac{1}{1+\left(x / x_{0}\right)^{2}}
$$

1s Included in the inveotigation, For this apectrum the intograttion in (38) can be done analytically to ylold (c), (28)) 


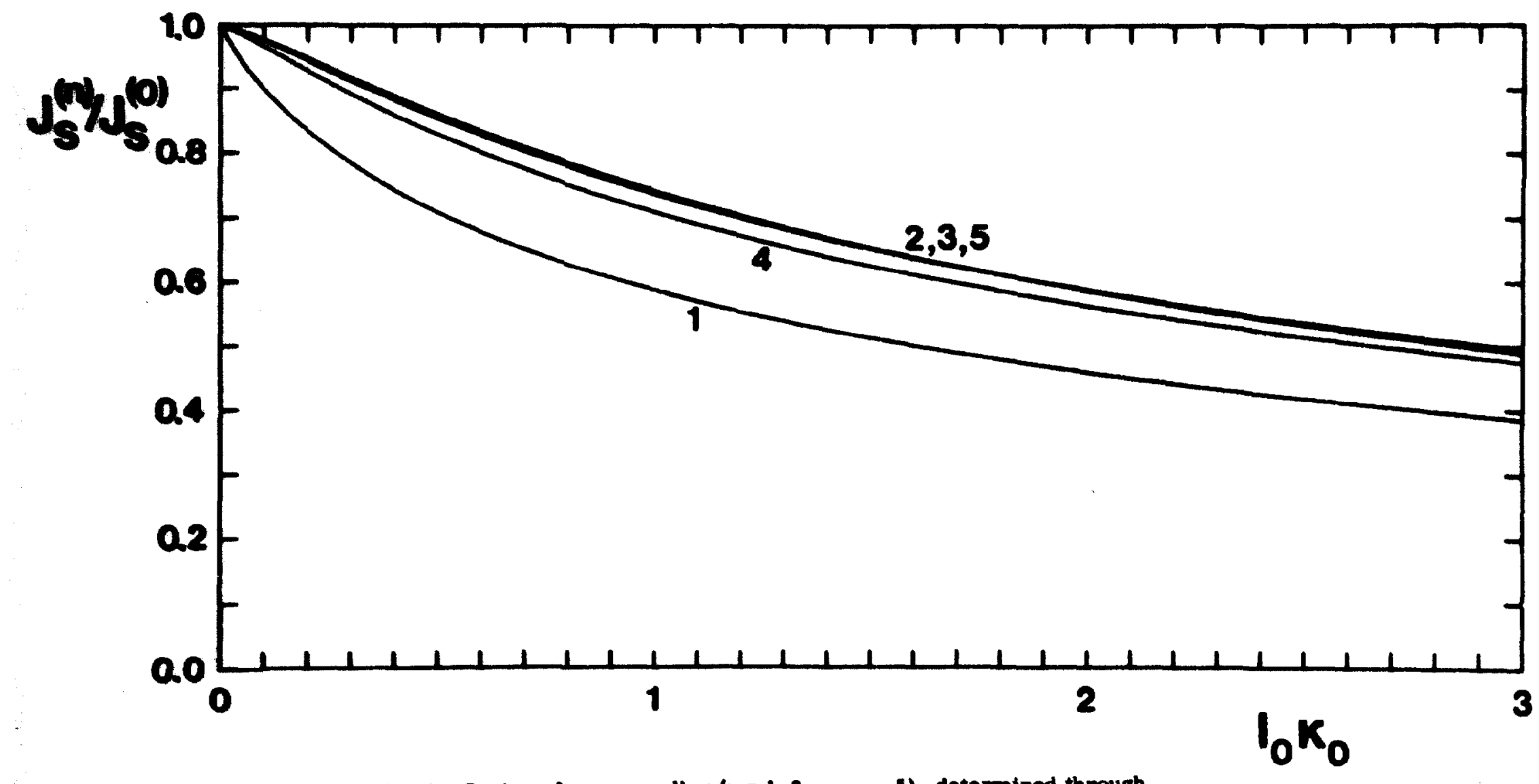

F16. 4. Ratice of overopeedine $(n-1,2, \ldots, 5)$, determined through

(32-36). The enemometer distance constant $l_{0}$ la made non-dimenatonal

by the turbulent poek wavonumber " 0 " 


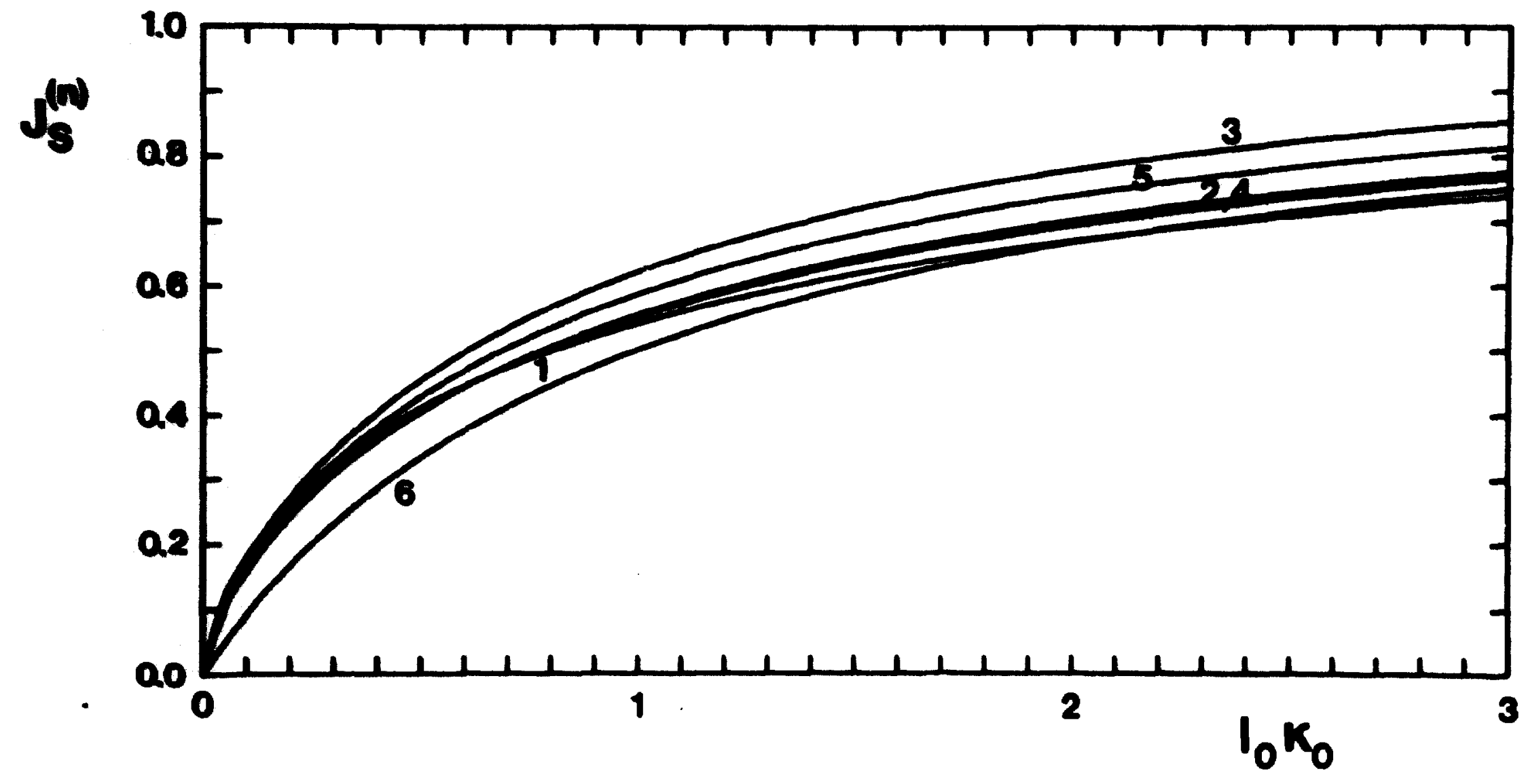

Fig. 8. The reletive overepectling tivided by the equare of the hortecontal

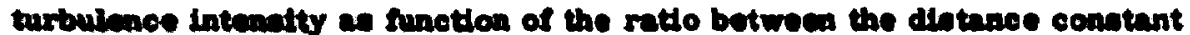
$2_{0}$ and the marisontal leapth coelo of the turbulence $\left(1 / \mathrm{m}_{0}\right)$. Curva no. 6 correapondo to (40) and (42). 
$J_{s}^{(6)}=l_{0} x_{d} /\left(1+l_{0} w_{0}\right)$

Fig. 5 shows $J_{s}^{(n)},=1,2, \ldots 6$, as a function of $\ell_{0} \ldots_{0}$

\section{CONCLUDING REMARKS}

A statistical method was applied to a general cup-anemometer equation of motion in order to determine the overestimation of the mean wind apeed in a turbulent wind. It was shown that the overspeeding depends not only on the turbulence intensity, but also on the chape of the apeed enerEJ-spectrum, $\varphi_{g}(h)$. If the energy-conthining part of the epectrum is well deacribed in terms of the variance and a length scale $A_{s}$, then the relative overspeeding AS/S can be written

$$
\frac{\Delta S}{S}=I_{8}^{2} J_{8}\left(l / A_{g}\right)+c I_{\nabla}^{2}
$$

where $I_{s}$ and $I_{w}$ are the horizontal and the vertical turbulence intensity, respectively, $l_{0}$ is the cup-anemometer distance conotant, $J_{s}$ a function of $\ell_{\mathrm{o}} J_{\mathrm{s}}$, and $\mathrm{c}$ a constant. Both $J_{\mathrm{g}}$ and $\mathrm{c}$ are believed to be less than unity, and consequently the relative overspeeding can never exceed the oum of $I_{8}^{2}$ and $I_{i=}^{2}$.

If the formula is applied to a situation where $l_{0}$ is much less than the integral scale of the horizontal turbulence, then, from quite general assumptions about the exdstence of an inertial subrange and Monin-Obulhov similarity with local balance between production and dissipation of turbulent energy, we conclude that only in extreme canes does the overepeeding amount to more than $10 \%$ Such cases may occur when the ratio between $l_{0}$ and the height of observation is of the order of 10 or more. Even then $A S / S$ is over.. estimated if a correction for the fintte magnitude of the integral scale is not taken into consideration (cl, Al. 4).

For practical purposes it is shown (ce, fis. 5) that if the characteriotic

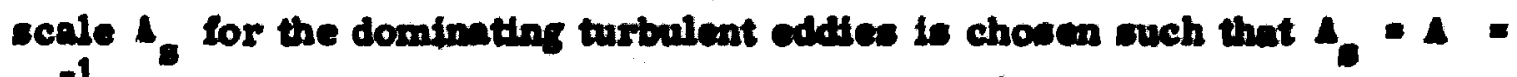
${ }_{0}^{-1}$, where to it the pealk wave number for the logerdthmic enercy opectirum (cl. 4f. 3), then

$$
J_{D}=\left(1+\Delta / t_{0}\right)^{-1}
$$


will roughly describe the behaviour of the scale-dependent part of the overspeeding.

While the final manuscript was being prepared, Dr. J.C. Wyngaard of the Cooperative Institute for Research in Environmental Sclences, Boulder, brought to our attention an unpublished paper by E. I. Kaganov and A. M. Yaglom of the Institute of Atmospheric Physics, Academy of Sciences, Moscow, USSR, in which the overspeeding problem is treated in much the same way as in the present paper. A. M. Yaglom has informed us (personal communication) that he obtained the basic equation (18) in the early fifties and published the result in a paper (Yaglom, 1954) that has remained virtually unknown outside the USSR. 


\section{REFERENCES}

Busch, N. E., 1965: A micrometeorological data-handling system and some preliminary results. Risp Report No. 99, 92 pp.

Carl, D. M., T.C. Tarbell, and H. A. Panofsky, 1973: Profiles of wind and temperature from towers over homogeneous terrain. J. Atmos. Sci., 30, 788-794.

Davenport, A.G., 1961 : The spectrum of horisontal gustiness near the ground in high winds. Quart. J. Roy. Meteorol. Soc., 87, 194-211.

Kaganov, E. I., and A. M. Yaglom, 1975: Errors in wind speed measurements by rotation anemometers (submitted to Boundary-Layer Meteorology).

Kaimal, J. C., J.C. Wyngaard, Y. Izumi, and O. R. Coté, 1972: Spectral characteristics of surface-layer turbulence. Quart. J. Roy. Meteorol. Soc. , 98, 563-589.

Kaimal, J.C., 1973: Turbulence spectra, length scales and structure parameters in the stable surface layer. Boundary-Layer Meteorol. 4. 289-309.

von Kármán, T., 1948 : Progress in the statistical theory of turbulence. Reprinted in Turbulence, Closeic Papers on Statistical Theory. New York 1961, Interscience Publisher, 162-174.

Wyngaard, J. C. , J. T. Bauman, and R. A. Lynch, 1973: Cup anemometer dynamics. Proc. Instrument Society of America, Pittsburgh, Vol, 1, 701 - 708.

Yaglom, A. M., 1854: On allowing for inertia of meteorological instruments in a turbulent atmoophere. Trudy Geofix. Int. Akad. Nauk SSSR No. 24 (151), 112-163 (in Rusaian). 
IBDN 87-5s0-0585-0 